\title{
Response and Recovery
}

\section{Marvin L. Birnbaum, MD, PhD; co-authored by Patrice Kohl, BA ${ }^{1}$}

How wretched are the minds of men, and how blind their understanding

(O miseras hominum mentes! Of pectoral caca!)

Lucretius

De Rerum Natura, Bk. ii, 1.472

To be bored by essentials is characteristic of small minds.

R.U. Johnson

Poems of Fifty Years: Preface

Once again, the lack of universal terminology is hampering efforts to move disaster medicine forward-this time, as it relates to the longitudinal phases of a disaster. During a World Health Organization (WHO) meeting I attended in December, confusion ensued as meeting participants discussed the transition period between the response and development phases of a disaster. Participants generally agreed this period has been largely neglected, but disagreed over how it should be defined. Some refused to recognize this period as anything more than a transition between two phases while others, myself included, believed that between relief and development there is yet another phase-the recovery phase.

Failure to recognize the recovery phase of the disaster has resulted in dire consequences. Because this phase has not been recognized fully, resources allocated for this period have been inadequate. Between the relief phase, the phase in which the response to a disaster focuses on life saving, and the development phase, the phase in which the effected society becomes stronger and more resilient than it was before the disaster occurred, a society must first return to its pre-event status. Or in other words, recover.

Some of the WHO meeting participants who did not recognize a recovery phase seemed to believe that it was not a phase because responders' goals should and most often do aim higher than recovery from a disaster. These participants argued that because the overall disaster response goal aims not only to restore society to its preevent status, but to make the society stronger and more resilient than it was before the disaster so that a disaster is less likely to occur again. For example, following the devastating 2004 Indian Ocean tsunami, former US President Bill Clinton said the aim of the disaster response should be to "build it back better". But just because an affected society and responders aim to "build back better" does not mean they can skip the critical step of recovery in between.

Debate and confusion over the longitudinal phases of a disaster were deepened by the misconception that there are distinct cutoffs between longitudinal phases. In real- ity, the phases tend to overlap one another. In some cases, for example, the responses may begin while the event still is ongoing. The fact that the phases of a disaster often run concurrently makes evaluation of a disaster and disaster research very difficult. In order to compare the efficacy of various interventions, however, evaluators must first be able to identify which phase of a disaster an intervention's goals were aimed toward. Consequently, it is imperative that the disaster health community clearly identify and define the phases of a disaster. In the effort to sort out the confusion over disaster terminology and the longitudinal phases of a disaster, the Task Force for Quality Control of Disaster Management has made great headway. ${ }^{1}$

The Task Force for Quality Control of Disaster Management has invested years of careful work into building a structure that can be used to evaluate and better understand disasters and disaster responses. The results of the task force's work have launched a series of published volumes under the title, Health Disaster Management: Guidelines for Evaluation and Research in the Utstein Style. The fist volume of this series already has been published, and a second volume will be published soon.

In the first volume, recovery emerges as a central theme and the task force addresses several issues key to understanding this phase of the disaster as well as the relief and development phases. The task force, for example, dispels some of the confusion over the use of the word response. The task force explains that a response is an answer to a need, an explanation that indicates why referring to the relief phase of a disaster as the response phase is misguided. Because there are needs in each of the phases of the disaster and a response is an answer to a need, to label a single phase as the response phase is misleading. In the relief phase, responses are needed to contain the loss of life or provide relief to prevent further deterioration; in the recovery phase, responses are needed to promote recovery to the pre-event state, and in the development phase, responses are needed to strengthen a society beyond its pre-disaster status. Consequently, although responses occur during the relief phase of the disaster, it is inappropriate to label the relief as the response phase. The responses that occur during the relief phase of the disaster include only life-saving activities such as search and rescue efforts and providing bottled water to limit the number of lives lost.

Responses that aim to restore the functions of the stricken society back toward their pre-disaster functional state, on the other hand, are what make up the recovery phase. Refusal to recognize this phase and instead recognize only a transition between relief and develop- 
ment creates confusion over the purpose of the responses made in the wake of disasters, and draws attention away from the need to help a society recover.

Fully recognizing the recovery phase of the disaster could help boost the resources allocated to this critical phase following a disaster. As of now, the great bulk of donor aid targets life-saving activities occurring during the relief phase, while few resources are allocated to responses that help disaster-afflicted societies recover. Where have all those displaced people from the tsunami gone? Are we still trying to maintain them in camps or do they continue to live in the homes of relatives and friends? When relief needs are met, most responders who have provided assistance pack their bags and go home.

In a conference titled "What Happens after Everyone Leaves?", convened by Gloria Leon and Victor Koscheyev at the University of Minnesota in 1994, it was noted that most disaster responders leave when the needs are the greatest. Have the Gulf States in the US returned to their pre-Katrina status? Has the tourist industry in the Maldives returned to where it was pre-tsunami? Resources must be directed to recovery.

Recognition of recovery as a disaster phase must become universal. Without the recognition and focused response on the recovery phase of a disaster, the disaster may never truly end. In the first volume of the Utstein Guidelines, the task force notes that a disaster is not over until the affected elements of society have returned to their pre-event state. To determine whether recovery has occurred, we must ask questions such as, has the health status of the population devastated by Hurricane Katrina returned to normal? Have the homes of all of those displaced by the Indian Ocean tsunami been rebuilt and repaired? Until the answers to these questions is yes, the Katrina and Indian Ocean tsunami disasters are ongoing.

To determine whether development has occurred, we must ask questions such as, are the Katrina-hit regions of the south more prepared should another powerful hurricane arrive than before Katrina? Are any of those affected by Indian Ocean tsunami better off now than they were before the tsunami? When the answer to these two questions is yes, then development has occurred.

Before any response occurs, it is imperative to know whether its goal is to prevent or minimize further loss of life, to restore the society to its pre-disaster status, or strengthen a society above and beyond its pre-event status. If this is not done, the efficacy and benefits of the response cannot be properly evaluated.

The period between the relief and development is more than just a transition, it is a phase of the disaster critical to identifying when a disaster has ended and that allows a society to get back up on its own feet. In the aftermath of a disaster, disaster responders are not only responsible for preventing further loss of life, they are also responsible for helping the society regain self-sufficiency, livelihoods, and its way of life. In order to do so, we must direct our wellmeaning assistance to help them recover.

We must view with profound respect the infinite capacity of the buman mind to resist the introduction of useful knowledge.

Thomas R. Lounsbury

Lockwood, The Freshman and His College, p 44.

The buman understanding is naturally right, and has within itself a strength sufficient to arrive at the knowledge of truth, and to distinguish it from error.

References

1. Sundnes KO, Birnbaum ML (eds), Task Force for Quality Control of Disaster Management: Health Disaster Management: Guidelines for Evaluation and Research in the Utstein Style. Prehospital Disast Med 2003; 17;Suppl 3.

${ }^{1}$ WADEM Publications Editor currently collaborating with the World Health Organization South East Asia Office on a book on the 2004 Indian Ocean tsunami. Note, Kohl did not attend the WHO meeting referred to in the editorial. 